ISSN 1110-0230

\title{
Semi-Solid Agar Medium for Detection of Fungal Enzymes
}

Muhanna, N.A.S.

\author{
Plant Pathology Research Institute, Agricultural Research \\ Center, Giza, Egypt.
}

The fungal plant pathogens were isolated from different host plants grown at different locations in Egypt. Alternaria alternata, Alternaria solani, Curvularia lunata, Fusarium solani, Fusarium oxysporum, Macrophomina phaseolina, Pyrenochaeta lycopersici, Rhizoctonia solani, Stemphylium botryosum, Trichoderma viride and Thielaviopsis basicola were recovered. Polygalacturonase (PG), chitinase $(\mathrm{CH})$, cellulase $(\mathrm{Cx})$ were determined using a suggested modified plate method with very low agar content $(5 \mathrm{gm} / \mathrm{l})$. All fungal isolates produced remarkable activity of $\mathrm{PG}, \mathrm{CH}$ and produced less cellulase $\left(81.8 \%\right.$ frequency) at $28^{\circ} \mathrm{C}$. Six isolates $(54.5 \%)$ were scored active PG producers namely $T$. viride, $T$. basicola, $F$. oxysporum, $P$. lycopersici, M. phaseolina, S. botryosum, four isolates $(36.4 \%)$ were moderate in this regard, $R$. solani $(9.1 \%)$ was scored non producer at $21^{\circ} \mathrm{C}$. Similar variation in $\mathrm{Cx}$ for the activity of three fungal isolates $(27.3 \%)$ was recognized as active producers for $T$. viride, $T h$. basicola, $F$. oxysporum and three isolates $(27.3 \%)$ were scored as moderate producers for $P$. lycopersici, $F$. solani, A. solani. on the other hand, five isolates, $(45.5 \%)$ were found to be non-producers in this regard, A. alternata, $R$. solani, M. phaseolina, S. botryosum and $C$. lunata at $21^{\circ} \mathrm{C}$. Moreover, two fungal isolates (18.2\%) were highly active producers of chitinase $(\mathrm{CH})$ activity for $F$. oxysporum and $F$. solani. Three isolates $(27.3 \%)$ failed to produce chitinase $(\mathrm{CH})$ under the conditions of the experiment for A. alternata, $R$. solani, $M$. phaseolina, though six isolates $(54.5 \%)$ were found to be moderate chitinase $(\mathrm{CH})$ producers by A. solani, C. lunata, P. lycopersici, S. botryosum, T. viride and T. basicola. Seven fungal isolates $(63.6 \%)$ reacted positively at higher temperature $\left(28^{\circ} \mathrm{C}\right)$ and higher production of $(\mathrm{PG}),(\mathrm{CH})$ and $(\mathrm{Cx})$. The highest temperature tends to increase qualitatively the enzyme activity, while lower temperature decreased such effect. Four isolates, $F$. oxysporum, Th. basicola, T. viride, and $P$. lycopersici were scored active $\mathrm{PG}, \mathrm{CH}$ and $\mathrm{Cx}$ at two different temperatures, 21 and $28^{\circ} \mathrm{C}$, at four days incubation. It is worth noting that the semi solid agar medium $(5 \mathrm{gm}$. agar/l) is being favorable for accurate detection of PG, $\mathrm{Cx}$, and $\mathrm{CH}$. Further trial with the modified semi-solid agar medium for evaluation of other enzymes involved in pathogenicity are needed.

Keywords: Bromo cresol purple, chitinase, cellulase, N-acetylglucosamine, semi-solid agar, $\mathrm{PG}, \mathrm{Cx}, \mathrm{CH}$, relative enzyme. 
Plant pathogenic organisms are able to produce a wide range of cell-walldegrading enzymes (Amit et al., 2014). The pectinases (a group of pectinolytic enzymes) are the first enzymes considered by most fungal pathogens when attacking plant cell walls, followed by hemicellulases and cellulases (Vallejo Herrera et al., 2004). Pectinase is produced by a large number of microorganisms including bacteria, actinomycetes, yeasts, and filamentous fungi (Gomes et al., 2009).

A positive correlation has been established between the production of pectinolytic enzymes, virulence and disease symptoms in several path systems (Kikot et al., 2009). Gawade et al., (2017) reported that pathogenic fungi are producing large quantities of PG in culture and in inoculated tissue is being correlated with their virulence.

Many plant pathogenic organisms are capable of degrading cellulose by producing a cellulase complex which involves the synergistic action of three main enzymatic complexes, endoglucanase, exoglucanase that releases either glucose or cellobiose, and $\beta$-1,4-glucosidase that hydrolyzes cellobiose and cellodextrins to glucose (Okunowo et al., 2010). Fungi belonging to genera such as Trichoderma, Penicillium, Aspergillus, Myrothecium, Fusarium and Chaetomium species etc., produce cellulases under suitable conditions (Sherief et al, 2010).

Zhang et al. (2014) reported that $\mathrm{Cx}$ degrades cellulose to cellobiose and is being correlated with virulence of pathogens (Zhou et al., 2016). The activity has been observed in culture and in diseased tissue inoculated with pathogens such as Colletotrichum acutatum (Fernando et al., 2001) and Fusarium sulphureum (Yang et al., 2012). Thanatephorus cucumeris (Zhao et al., 2014).

Chitin is one of the most abundant nitrogenous carbohydrate of ecosystem (Schickler et al., 1998). It is composed of $\beta$-(1-4) linked N-acetyl-D-glucosamine units. Chitinases are chitin-degrading enzymes that hydrolyze the $\beta$-1, 4-glycosidic bonds between the $\mathrm{N}$-acetyl glucosamine residues of chitin and are widely distributed in nature (Kitamura and Kamei, 2003). They are well known producers of chitinolytic enzymes and used commercially as a source of these components. Additional interest in these enzymes is stimulated by the fact that chitinolytic strains of Trichoderma are among the most effective agents of biological control of plant diseases (Karlsson et al., 2010). Using natural substrates or derived from natural one, the detection of enzyme activity relies on chemical redox reaction (Ferrari et al., 2014). Fungal chitinase have also been observed to play a key role in the nutrition, morphogenesis, and developmental processes in fungi (Sharma et al., 2018).

The optimum growth temperatures for the majority of fungi has been to fall between temperature(s) $25^{\circ} \mathrm{C}$ to $30^{\circ} \mathrm{C}$. Above $40^{\circ} \mathrm{C}$, the growth is being retarded poor and, in some cases, mortality may occur (Sharma and Rajak, 2003). In earlier reports, $F$. oxysporum was found to reach its maximum growth rate at between 25 -

Egypt. J. Phytopathol., Vol. 47, No. 2 (2019) 
$30^{\circ} \mathrm{C}$ (Mogensen et al., 2009). Trichoderma viride has been reported to reach its maximum growth at $30^{\circ} \mathrm{C}$ (Ramanathan and Vinodhkumar, 2013).

Plant pathogenic fungi actively kill and degrade plant tissue and utilize liberated carbohydrates and proteins compounds for growth and reproduction (King et al., 2011). The mechanism involved in pathogenicity is by mainly secreting enzymes (King et al., 2011) and hence the pathogen was screened for different enzymes.

A number of fungal molecules, like cell wall degrading enzymes (CWDEs), pathogen related proteins and enzymes involved in toxin synthesis, are known to contribute to fungal pathogenicity and virulence (Gonzalez-Fernandez and JorrinNovo, 2012).

The present study was following extracellular fungal enzymes on semi-solid agar medium like polygalacturonase $(\mathrm{PG})$, chitinase $(\mathrm{CH})$, cellulase $(\mathrm{Cx})$ at different temperatures. Screening, isolation characterization and production of more efficient extracellular enzyme producing fungi, were considered.

\section{Materials and Methods}

Fungal isolates and identification

The tested fungi were isolated from different plant species, locations and the pathogenic fungi were recovered, tested and maintained on slants of potato dextrose agar (PDA) at $4^{\circ} \mathrm{C}$. Identification was carried out according to their cultural and morphological features according to the descriptions of Neergaard, (1945), Hansford, (1946), Rifai (1969), Barnett and Hunter (1972), Nelson et al., (1983), Carling and Summer (1992). Species identification was run by examining both macroscopic and microscopic features of a seven-day old pure cultures.

\section{Experimental design:}

The experimental design was considering media, isolates, temperature, and enzymes, with three replications, each replicate consisted of a single Petri dish (90 $\mathrm{mm}$ diameter). Control treatments were all the media not colonized by the fungi isolates.

Modified agar medium for detection of fungal enzymes:

Detection medium (Agrawal and Kotasthans, 2012) was used in principle after modification. Data (Table 1) show the basal medium comprising (g/liter) 0.3 $\mathrm{MgSO}_{4} .7 \mathrm{H}_{2} \mathrm{O}, 3.0\left(\mathrm{NH}_{4}\right)_{2} \mathrm{SO}_{4}, 2.0 \mathrm{KH}_{2} \mathrm{PO}_{4}, 1.0$ citric acid monohydrate, 5 agar, 0.5 $\mathrm{Na}_{2} \mathrm{SO}_{3}, 5.0$ Peptone, 4.5 colloidal chitin or cellulase or Polygalacturonase or non and 0.15 bromo cresol purple; $\mathrm{pH}$ was adjusted to 7.0 and then autoclaved at $121^{\circ} \mathrm{C}$ for 15 min. (suggested modified solid medium).

It is worth noting that solidification of the agar was made by only $5 \mathrm{~g}$ agar and $0.5 \mathrm{~g} \mathrm{Na}_{2} \mathrm{SO}_{3}$. The peptone ingredient was added to give optimal growth. 
Fungal isolates growth was evaluated based on the development of the mycelium on the partly solidified suggested medium. The plates were inoculated with a $5 \mathrm{~mm}$ diameter agar disc taken from the actively growing mycelium on PDA medium incubated at 21 and $28^{\circ} \mathrm{C}$ for 4 days and finally the assay was carried out in three replicates and data were presented as mean.

It is worth noting that the suggested medium was different from that of Agrawal and Kotasthans (2012) in the degree of agar setting of the medium that being added as only $5 \mathrm{~g}$ agar in addition to $0.5 \mathrm{~g} \mathrm{Na}_{2} \mathrm{SO}_{3}$, sodium sulphite and $5.0 \mathrm{~g}$ peptone to detect enzyme(s) in partly semi solid matrix, tentatively resembling plant tissues, instead of the usual liquid assays. The components of the assay medium are shown in Table (1).

Table (1): Composition of the medium.

\begin{tabular}{|c|l|c|c|c|c|}
\hline No. & \multicolumn{1}{|c|}{$\begin{array}{c}\text { Components of } \\
\text { medium/ }\end{array}$} & Control & Pectin & Cellulose & Chitin \\
\hline$* 1$ & Agar & $5.0 \mathrm{~g}$ & $5.0 \mathrm{~g}$ & $5.0 \mathrm{~g}$ & $5.0 \mathrm{~g}$ \\
\hline 2 & Substrate & - & $4.5 \mathrm{~g}$ & $4.5 \mathrm{~g}$ & $\begin{array}{c}\text { N-Acetyle } \\
\text { glucosamine } \\
4.5 \mathrm{~g}\end{array}$ \\
\hline 3 & $\mathrm{MgSO}_{4} \cdot 7 \mathrm{H}_{2} \mathrm{O}$ & $0.3 \mathrm{~g}$ & $0.3 \mathrm{~g}$ & $0.3 \mathrm{~g}$ & $0.3 \mathrm{~g}$ \\
\hline 4 & $\left(\mathrm{NH}_{4}\right)_{2} \mathrm{SO}_{4}$ & $3.0 \mathrm{~g}$ & $3.0 \mathrm{~g}$ & $3.0 \mathrm{~g}$ & $3.0 \mathrm{~g}$ \\
\hline 5 & $\mathrm{KH}_{2} \mathrm{PO}_{4}$ & $2.0 \mathrm{~g}$ & $2.0 \mathrm{~g}$ & $2.0 \mathrm{~g}$ & $2.0 \mathrm{~g}$ \\
\hline 6 & $\mathrm{Citric} \mathrm{acid} \mathrm{monohydrate}$ & $1.0 \mathrm{~g}$ & $1.0 \mathrm{~g}$ & $1.0 \mathrm{~g}$ & $1.0 \mathrm{~g}$ \\
\hline$* 7$ & $\mathrm{Na}_{2} \mathrm{SO}_{3}$ & $0.5 \mathrm{~g}$ & $0.5 \mathrm{~g}$ & $0.5 \mathrm{~g}$ & $0.5 \mathrm{~g}$ \\
\hline$* 8$ & Peptone & $5.0 \mathrm{~g}$ & $5.0 \mathrm{~g}$ & $5.0 \mathrm{~g}$ & $5.0 \mathrm{~g}$ \\
\hline 9 & Bromo cresol purple & - & $0.15 \mathrm{~g}$ & $0.15 \mathrm{~g}$ & $0.15 \mathrm{~g}$ \\
\hline 10 & PH & 7 & 7 & 7 & 7 \\
\hline
\end{tabular}

* The stepwise sequence of the study.

1- Fungal inocula on PDA at $\mathrm{pH} 7$.

2- Fresh culture of fungi in concern propagated and inoculated on different substrates at two different temperature levels, 21 and $28^{\circ} \mathrm{C}$ for 4 days.

3- Observation of color change from yellow (acid) to purple (alkaline). The color of the medium before autoclaving is purple, shifted to yellow after $\mathrm{pH}$ drop caused by autoclaving and again to purple by the action of enzymes.

4- Three replicates for each isolate.

5- Measurement of extracellular enzyme activity on the plate was made in three replicates. For each replicate, the diameter of the colony growth and the surrounding halo was carried out. The index of relative enzyme activity (RA) was calculated according to Krishnan et al. (2011).

Egypt. J. Phytopathol., Vol. 47, No. 2 (2019) 


$$
\text { Relative enzyme activity }(\mathrm{RA})=\frac{\text { Colored halo diameter }- \text { Colony diameter }}{\text { Colony diameter }}
$$

6- For the screening it was determined that a RA value of 1 or greater was classified as having significant enzyme activity (Duncan et al., 2008).

Enzymes activity:

Cellulase activity $(C x)$ :

Cellulase secretion was detected by growing fungi in the modified agar medium. The plates were incubated at 21 and $28^{\circ} \mathrm{C}$ for three to seven days. Finally, plates were observed for the formation of yellow-colored haloes around the inoculated discs, following the method of Teather and Wood (1982).

Chitinase activity $(\mathrm{CH})$ :

Enzymatic hydrolysis of colloidal chitin was assayed following the release of free N-Acetyleglucosamine (NAG) from colloidal chitin by clearing halo assay method (Frandberg and Schnurer,1998).

Polygalacturonase activity $(P G)$ :

Polygalacturonase secretion was detected by growing fungi in agar medium. Clear halo formed around the fungal colony indicates pectinolytic activity (Bijesh et al., 2015). The diameter of colonies and clear zones were measured for calculation of relative enzyme (RA) activity.

Effect of temperature:

Temperature is also an important factor that influences the fungal extracellular enzyme activity also depends on the strain variation of the microorganism. The fungal cultures were plated on the suggested modified agar medium, using $0.5 \mathrm{~mm}$ cork borer disc, and incubated at both $21^{\circ} \mathrm{C}$ and $28^{\circ} \mathrm{C}$ for 4 days.

Statistical analysis:

Data were compared by the analysis of variance according to the procedures of Snedecor and Cochran (1980). Means of all treatments were compared by the least significant difference LSD at $5 \%$ level.

\section{Results}

Fungal isolation and identification:

The tested fungi were isolated from nine different diseased plants species, i.e., Bean, Cantaloupe, Eggplant, Lettuce, Pea, Pepper, Peanut, Spinach, Tomato collected from seven locations. The isolated fungi were identified according to their cultural and morphological characters as A. alternata, A. solani, C. lunata, F. solani, $F$. oxysporum, M. phaseolina, P. lycopersici, R. solani, S. botryosum, T. viride. and Th. basicola (Table 2). 
Table (2): Fungi isolated with their respective plant's species and locations.

\begin{tabular}{|c|c|c|c|c|}
\hline No. & Fungi & Host & $\begin{array}{l}\text { Plant } \\
\text { Organ }\end{array}$ & location \\
\hline 1 & Alternaria alternata (Fr.) Keissl & $\begin{array}{c}\text { Spinach } \\
\text { (Spinacia oleracea) }\end{array}$ & leaves & Giza \\
\hline 2 & Alternaria solani Sorauer & $\begin{array}{c}\text { Tomato } \\
\text { (Solanum } \\
\text { lycopersicum) }\end{array}$ & leaves & Fayoum \\
\hline 3 & $\begin{array}{l}\text { Curvularia lunata (Wakker) } \\
\text { Boedijn. }\end{array}$ & $\begin{array}{c}\text { Lettuce } \\
\text { (Lactuca sativa) }\end{array}$ & leaves & Sharqiya \\
\hline 4 & Fusarium solani (Mart.) Sacc. & $\begin{array}{c}\text { Pepper } \\
\text { (Capsicum annuum) }\end{array}$ & crown & Damiaetta \\
\hline 5 & $\begin{array}{l}\text { Fusarium oxysporum } \\
\text { Snyder \& Hansen }\end{array}$ & $\begin{array}{c}\text { Cantaloupe } \\
\text { (Cucumis melo) }\end{array}$ & stem & Nobariya \\
\hline 6 & $\begin{array}{l}\text { Macrophomina phaseolina } \\
\text { (Tassi) Goid. }\end{array}$ & $\begin{array}{c}\text { Bean } \\
\text { (Phaseolus vulgaris) }\end{array}$ & root & Qaluobiya \\
\hline 7 & $\begin{array}{l}\text { Pyrenochaeta lycopersici } \\
\text { Schneid. \& Gerlach. }\end{array}$ & $\begin{array}{c}\text { Tomato } \\
\text { (Solanum } \\
\text { lycopersicum) }\end{array}$ & root & Qaluobiya \\
\hline 8 & Rhizoctonia solani Kühn & $\begin{array}{c}\text { Eggplant } \\
\text { (Solanum melongena) }\end{array}$ & crown & Qaluobiya \\
\hline 9 & Stemphylium botryosum Wallr & $\begin{array}{c}\text { Lettuce } \\
\text { (Lactuca sativa) }\end{array}$ & leaves & Nobariya \\
\hline 10 & Trichoderma viride Pers. & $\begin{array}{c}\text { Peanut } \\
\text { (Arachis hypogaea) }\end{array}$ & root & Ismailiya \\
\hline 11 & $\begin{array}{c}\text { Thielaviopsis basicola } \\
\text { (Berk. \& Broome) Ferraris }\end{array}$ & $\begin{array}{c}\text { Pea } \\
\text { (Pisum sativum) }\end{array}$ & root & Sharqiya \\
\hline
\end{tabular}

Colony radial growth:

Data presented in Table (3) and Fig (1) show that the isolated fungi when incubated at $21^{\circ} \mathrm{C}$ for 4 days grew significantly faster on medium (control) than those amended with different substrates namely pectin, cellulose and chitin. $T$. viride, Th. basicola, P. lycopersici, M. phaseolina, R. solani, F. oxysporum, $S$. botryosum, F. solani, C. lunata, A. solani, A. alternata, respectively, were recovered and identified. The amended substrates retarded growth significantly compared to control. T. viride grew significantly better on pectin $(6.0 \mathrm{~cm}$.), followed by $P$. lycopersici, M. phaseolina, and A. solani $(4.0 \mathrm{~cm}$.) respectively. Meanwhile, $F$. oxysporum, F. solani, Th. basicola, S. botryosum, R. solani, A. alternata and $C$. lunata showed limited growth on media amended with pectin, being $2.5-3.5 \mathrm{~cm}$. With chitin substrate, however $F$. oxysporum, A. solani, $F$. solani grew better, being 5.0, 5.0, $4.0 \mathrm{~cm}$., followed by $T$. viride, $S$. botryosum, $P$. lycopersici $(3.0 \mathrm{~cm})$. Furthermore $T$. viride, $F$. oxysporum and $T h$. basicola grew significantly better on cellulose amended media $(4.0 \mathrm{~cm}$.) and relatively followed by $A$. solani, $P$. lycopersici (3.0 and $2.5 \mathrm{~cm}$.), respectively.

Egypt. J. Phytopathol., Vol. 47, No. 2 (2019) 
Under relatively higher incubation temperature at $28^{\circ} \mathrm{C}$ for 4 days, seven isolates were grown on media (control) without any substrate in concern $T$. viride, Th. basicola, P. lycopersici, M. phaseolina, R. solani, $F$. oxysporum, $F$. solani $(9.0 \mathrm{~cm}$.). Meanwhile, $S$. botryosum, A. solani recorded $(8.5 \mathrm{~cm}$.), followed by A. alternata, $C$. lunata, being 8.0 and $7.5 \mathrm{~cm}$. respectively. Approximately similar radial growth was observed for pectin amended media. T. viride, $F$. oxysporum, $F$. solani, grew significantly better on pectin $(9.0 \mathrm{~cm}$.), P. lycopersici, A. solani $(8.0 \mathrm{~cm}$.) followed at a descending sequence by $S$. botryosum, $R$. solani, $(7.0 \mathrm{~cm}$.) and A. alternata, $M$. phaseolina, Th. basicola, C. lunata, being 6.0,6.0, 5.0, and $4.0 \mathrm{~cm}$., respectively.

On chitin supplemented medium, different growth rates were recorded for the tested fungi. $T$. viride, $F$. solani, $R$. solani grew significantly better $(8.0 \mathrm{~cm}$.) followed by $P$. lycopersici, $M$. phaseolina $F$. oxysporum, A. solani, S. botryosum, Th. basicola, A. alternata, being 7.0, 7.0, 6.0, 6.0, 6.0, 5.0 and $5.0 \mathrm{~cm}$. and last, $C$. lunata $(3.0 \mathrm{~cm}$.). Furthermore, supplemented cellulose promoted growth, $T$. viride, $F$. oxysporum recorded $8.0 \mathrm{~cm}$. while $F$. solani, $S$. botryosum recorded $7.0 \mathrm{~cm}$. followed by A. solani, Th. basicola, $R$. solani, $P$. lycopersic, A. alternata (6.5, 6.0, $6.0,5.0$, and $4.0 \mathrm{~cm}$.) and to less extend M. phaseolina, C. lunata (2.5, and $1.5 \mathrm{~cm}$.) as a weak cellulose decomposer.

Table (3): Screening for enzyme detection of isolates grown on modified agar plates.

\begin{tabular}{|c|c|c|c|c|c|c|c|c|}
\hline \multirow[b]{3}{*}{ Fungi } & \multicolumn{8}{|c|}{ Radial growth $(\mathrm{cm})$ after 4 days } \\
\hline & \multicolumn{4}{|c|}{$21^{\circ} \mathrm{C}$} & \multicolumn{4}{|c|}{$28^{\circ} \mathrm{C}$} \\
\hline & $\begin{array}{l}\overline{0} \\
\stackrel{\Xi}{0} \\
0\end{array}$ & 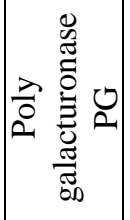 & 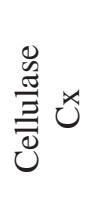 & 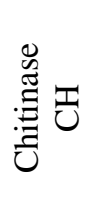 & 完 & 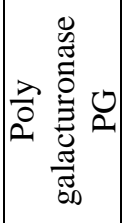 & 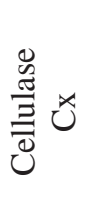 & 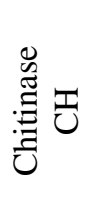 \\
\hline A. alternata & 4.5 & 2.5 & 1.5 & 1.5 & 8.0 & 6.0 & 4.0 & 5.0 \\
\hline A. solani & 5.0 & 4.0 & 3.0 & 5.0 & 8.5 & 7.0 & 6.5 & 6.0 \\
\hline C. lunata & 5.5 & 2.5 & 1.0 & 2.5 & 7.5 & 4.0 & 1.5 & 3.0 \\
\hline F. solani & 6.0 & 3.0 & 2.0 & 4.0 & 9.0 & 8.0 & 7.0 & 8.0 \\
\hline F. oxysporum & 7.0 & 3.5 & 4.0 & 5.0 & 9.0 & 9.0 & 8.0 & 6.0 \\
\hline M. phaseolina & 8.0 & 4.0 & 1.0 & 1.0 & 9.0 & 6.0 & 2.5 & 7.0 \\
\hline P. lycopersici & 9.0 & 4.0 & 2.5 & 3.0 & 9.0 & 8.0 & 5.0 & 8.0 \\
\hline R. solani & 7.5 & 2.5 & 1.0 & 2.5 & 9.0 & 8.0 & 6.0 & 7.0 \\
\hline S. botryosum & 6.5 & 3.0 & 1.0 & 3.0 & 8.5 & 7.0 & 7.0 & 6.0 \\
\hline T. viride & 9.0 & 6.0 & 4.0 & 3.0 & 9.0 & 9.0 & 8.0 & 8.0 \\
\hline Th. basicola & 9.0 & 3.0 & 4.0 & 2.5 & 9.0 & 5.0 & 6.0 & 5.0 \\
\hline LSD at $5 \%$ & 1.30 & 0.85 & 0.68 & 1.22 & 0.96 & 1.33 & 1.00 & 0.99 \\
\hline
\end{tabular}

Egypt. J. Phytopathol., Vol. 47, No. 2 (2019) 


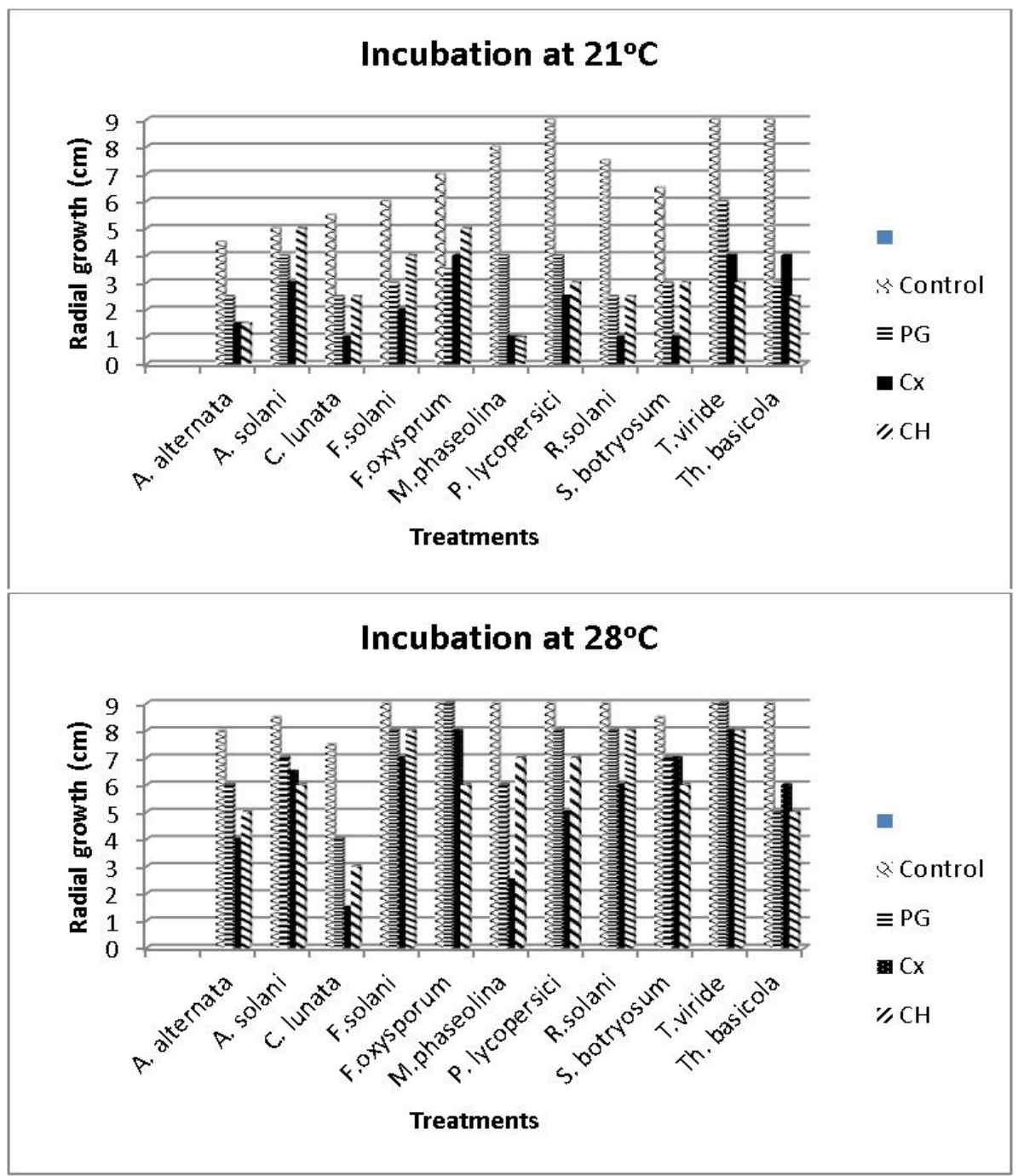

Fig (1): Radial growth of isolates grown on the different supplements at $21^{\circ} \mathrm{C}$ and $28^{\circ} \mathrm{C}$ for 4 days.

\section{Enzymes secretion:}

Determination of enzyme secretion related to time of inoculation, temperature and different substrates was carried out over a period of four days incubation. A distinct plate-colored halo of corresponding to enzyme(s) secretion is observed as compared to control. The results in (Fig.2) show the highest specific activity.

Egypt. J. Phytopathol., Vol. 47, No. 2 (2019) 
Enzymes detection at $21^{\circ} \mathrm{C}$ :

Results presented in Table (4), Fig ( 2 a and b) and Fig. ( 3 a, b, and c) show that polygalacturonase (PG) detection secreted by different fungi i.e., T. viride, $P$. lycopersici, F. oxysporum and Th. basicola after 4 days incubation at $21^{\circ} \mathrm{C}$, showed the large colored halos of hydrolysis by (PG) secretion, being $9.0 \mathrm{~cm}$. as indicated by change of color to purple followed by descending sequencer, M. phaseolina (7.0 $\mathrm{cm}$.), S. botryosum (6.0 cm.), A. solani $(5.0 \mathrm{~cm}$.), C. lunata $(4.5 \mathrm{~cm}$.), $F$. solani, A. alternata $(4.0 \mathrm{~cm}$.) and the least secretion was detected for $R$. solani, being $0.5 \mathrm{~cm}$.

Detection of cellulase (Cx) secreted by different fungi after 4 days incubation at $21^{\circ} \mathrm{C}$ showed that $T h$. basicola produced the largest halo of hydrolysis with $\mathrm{Cx}$, being $9.0 \mathrm{~cm}$. diameter followed by $T$. viride, $F$. oxysporum $(6.0 \mathrm{~cm}$.), and to less extent for A. solani $(4.0 \mathrm{~cm}$.), P. lycopersici $(3.5 \mathrm{~cm}$.) and $F$. solani $(3.0 \mathrm{~cm}$.). The failure of production, however, was reported for A. alternata, C. lunata, $S$. botryosum, M. phaseolina and $R$. solani, $(0.5 \mathrm{~cm}$.).

Chitinase $(\mathrm{CH})$ detection under the same conditions for $F$. oxysporum showed distinct colored halo of hydrolysis by $\mathrm{CH}$, being $7.0 \mathrm{~cm}$. followed by $F$. solani $(6.0$ $\mathrm{cm}$.), A. solani, P. lycopersici $(5.0 \mathrm{~cm}$.) and to less extent by $T$. viride $(4.5 \mathrm{~cm}$.), $T$. basicola, S. botryosum $(4.0 \mathrm{~cm}$.), C. lunata $(3.0 \mathrm{~cm}$.). The failure of detection, however, was reported for A. alternata, R. solani, M. phaseolina that did not show any change in color.

Enzymes detection at $28^{\circ} \mathrm{C}$ :

Polygalacturonase (PG) detection secreted by different fungi after 4 days at high incubation temperature at $28^{\circ} \mathrm{C}$, favored the growth of $T$. viride, P. lycopersici, $F$. solani, F. oxysporum, M. phaseolina, R. solani, A. solani, S. botryosum, Th. basicola, A. alternata produced large halo of hydrolysis with $\mathrm{PG}$, being $9.0 \mathrm{~cm}$. and to less extent by $C$. lunata, $(6.0 \mathrm{~cm}$.).

Cellulase $(\mathrm{Cx})$ secration by different fungi after 4 days incubation at $28^{\circ} \mathrm{C}$, is shown in Table (4). T. viride, P. lycopersici, F. oxysporum, F. solani, A. solani, S. botryosum, Th. basicola showed wide halo of hydrolysis, being $9.0 \mathrm{~cm}$. followed by A. alternata $(6.0 \mathrm{~cm}$.) and to less extent $M$. phaseolina $(3.5 \mathrm{~cm}$.), and impotent $\mathrm{Cx}$ secretion by $R$. solani, $C$. lunata $(0.5 \mathrm{~cm}$.) indicating failure of production under the conditions of the experiment.

Chitinase $(\mathrm{CH})$ production by different fungi after 4 days incubation at $28^{\circ} \mathrm{C}$ was reported by $F$. oxysporum, $F$. solani, A. solani, $T$. viride, P. lycopersici, $R$. solani, $S$. botryosum, M. phaseolina, Th. basicola as large zone of hydrolysis with chitinase, being $9.0 \mathrm{~cm}$. followed by A. alternata, C. lunata $(7.0$ and $5.0 \mathrm{~cm}$.).

All isolates tested were able to grow in the media with CMC as carbon sources and produced cellulolytic enzymes; however, their production potential was variable and was less active compared to polygalacturonase and chitinase. 
Table (4): Comparative determination of enzyme activity of the tested fungi incubated at different temperature levels.

\begin{tabular}{|c|c|c|c|c|c|c|c|c|c|c|c|c|}
\hline \multirow{3}{*}{ Fungi } & \multicolumn{6}{|c|}{ Enzymes activity at $21^{\circ} \mathrm{C}$} & \multicolumn{6}{|c|}{ Enzymes activity at $28^{\circ} \mathrm{C}$} \\
\hline & \multicolumn{2}{|c|}{ 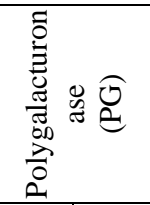 } & \multicolumn{2}{|c|}{ 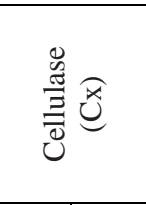 } & \multicolumn{2}{|c|}{ 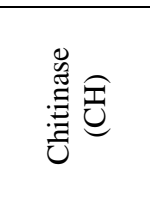 } & \multicolumn{2}{|c|}{ 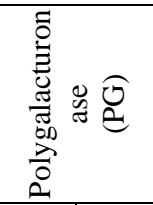 } & \multicolumn{2}{|c|}{ 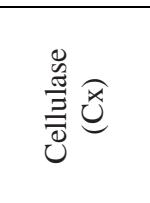 } & \multicolumn{2}{|c|}{$\stackrel{\mathscr{\Xi}}{\stackrel{\Xi}{\Xi}} \underset{\Xi}{\Xi}$} \\
\hline & $\begin{array}{l}\stackrel{3}{0} \\
\frac{0}{0}\end{array}$ & 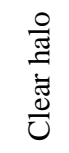 & $\begin{array}{l}\overrightarrow{0} \\
\frac{0}{0}\end{array}$ & 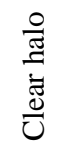 & $\frac{\overrightarrow{0}}{0}$ & 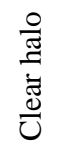 & $\begin{array}{l}\stackrel{\overrightarrow{0}}{0} \\
\frac{0}{0}\end{array}$ & 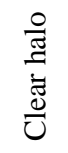 & $\frac{\lambda}{0}$ & 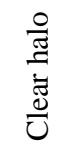 & $\begin{array}{l}\overparen{0} \\
\frac{0}{0} \\
ن\end{array}$ & 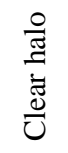 \\
\hline A. alternat & 2.5 & 4.0 & 1.5 & 0.5 & 1.5 & 0.5 & 6.0 & 9.0 & 4.0 & 5.0 & 5.0 & 7.0 \\
\hline A. solani & 4.0 & 5.0 & 3.0 & 4.0 & 5.0 & 5.0 & 7.0 & 9.0 & 6.5 & 9.0 & 6.0 & 9.0 \\
\hline C. lunata & 2.5 & 4.5 & 1.0 & 0.5 & 2.5 & 3.0 & 4.0 & 6.0 & 1.5 & 0.5 & 3.0 & 5.0 \\
\hline F. solani & 3.0 & 4.0 & 2.0 & 3.0 & 4.0 & 6.0 & 8.0 & 9.0 & 7.0 & 9.0 & 8.0 & 9.0 \\
\hline F. oxysporum & 3.5 & 9.0 & 4.0 & 6.0 & 5.0 & 7.0 & 9.0 & 9.0 & 8.0 & 9.0 & 6.0 & 9.0 \\
\hline M. phaseolina & 4.0 & 7.0 & 1.0 & 0.5 & 1.0 & 0.5 & 6.0 & 9.0 & 2.5 & 3.5 & 7.0 & 9.0 \\
\hline P. lycopersici & 4.0 & 9.0 & 2.5 & 3.5 & 3.0 & 5.0 & 8.0 & 9.0 & 5.0 & 9.0 & 8.0 & 9.0 \\
\hline R. solani & 2.5 & 0.5 & 1.0 & 0.5 & 2.5 & 0.5 & 8.0 & 9.0 & 6.0 & 0.5 & 7.0 & 9.0 \\
\hline S. botryost & 3.0 & 6.0 & 1.0 & 0.5 & 3.0 & 4.0 & 7.0 & 9.0 & 7.0 & 9.0 & 6.0 & 9.0 \\
\hline T. viride & 6.0 & 9.0 & 4.0 & 6.0 & 3.0 & 4.5 & 9.0 & 9.0 & 8.0 & 9.0 & 8.0 & 9.0 \\
\hline Th. basicola & 3.0 & 9.0 & 4.0 & 9.0 & 2.5 & 4.0 & 5.0 & 9.0 & 6.0 & 9.0 & 5.0 & 9.0 \\
\hline LSD at $5 \%$ & 0.85 & 1.22 & 0.68 & 0.96 & 1.22 & 1.30 & 1.33 & 1.53 & 1.00 & 1.82 & 0.99 & 1.08 \\
\hline
\end{tabular}

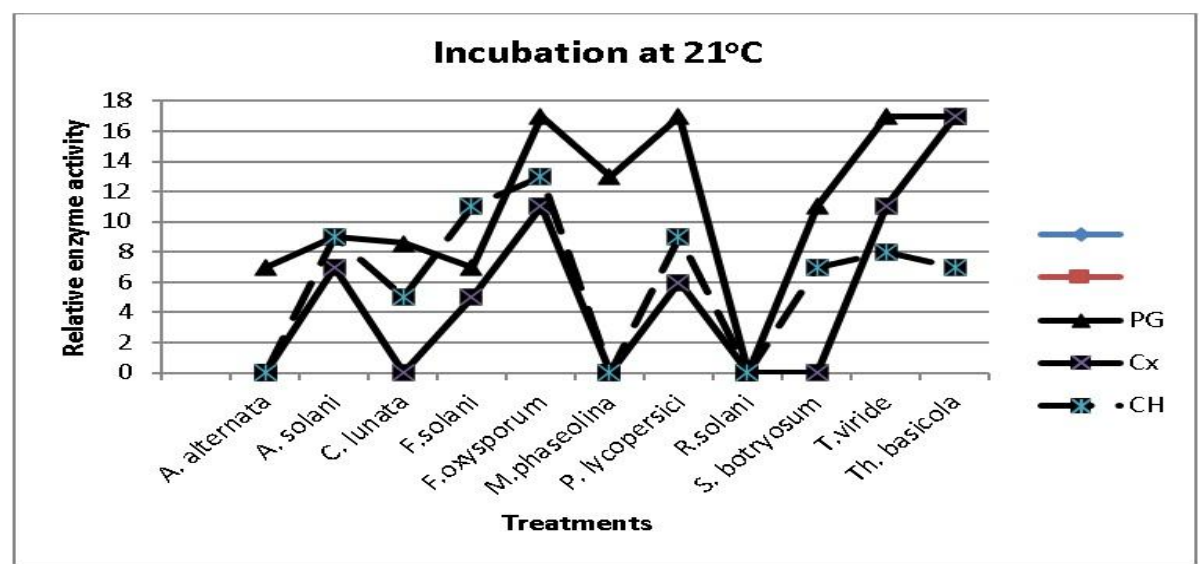

Fig. 2(a): Enzyme secretion pattern by isolated fungi at $21^{\circ} \mathrm{C} \mathrm{PG}, \mathrm{Cx}$, and $\mathrm{CH}$.

Egypt. J. Phytopathol., Vol. 47, No. 2 (2019) 


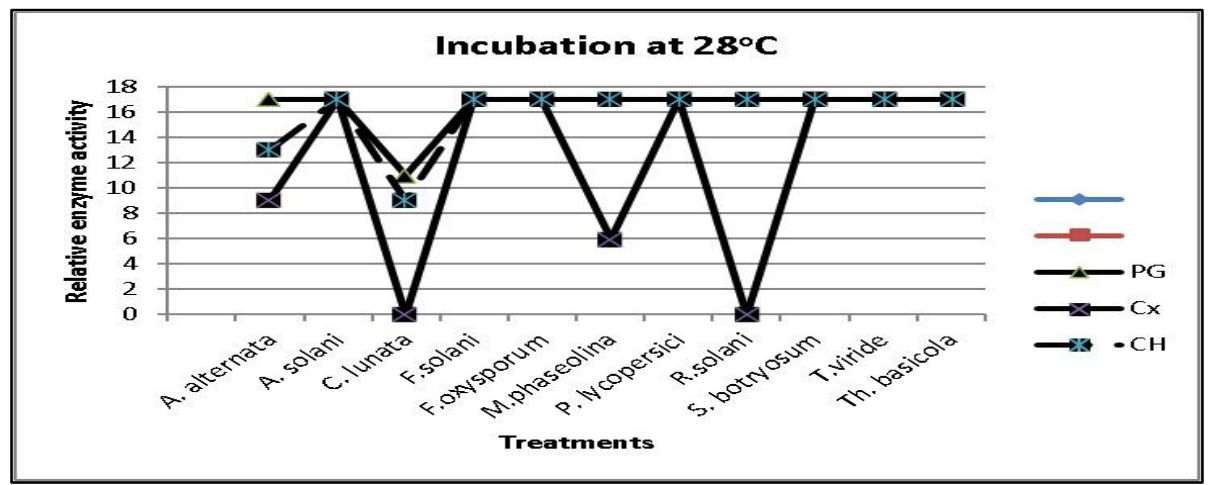

Fig. 2(b): Enzyme secretion pattern by isolated fungi at $28^{\circ} \mathrm{C}$. PG, Cx, and $\mathrm{CH}$.

Relative enzyme activity $(R A)$ of the isolated fungi:

Data in Table (5) show the maximal relative enzyme activity (RA), polygalacturonase $(\mathrm{PG})$, cellulase $(\mathrm{Cx})$, chitinase $(\mathrm{CH})$ of each of $T$. viride, Th. basicola, F. oxysporum, F. solani, A. solani, P. lycopersici, S. botryosum after incubation at $28^{\circ} \mathrm{C}$ for four days. The results show clearly that no secretion could be recognized for A. alternata, C. lunata, M. phaseolina, $R$. solani and $S$. botryosum at low temperature $\left(21^{\circ} \mathrm{C}\right)$ for the fungi Cellulase $(\mathrm{Cx})$, polygalacturonase $(\mathrm{PG})$ and chitinase $(\mathrm{CH})$.

Table (5): Relative enzyme activity (RA) of the isolated fungi after incubation at two different temperature levels.

\begin{tabular}{|c|c|c|c|c|c|c|}
\hline \multirow[b]{3}{*}{ Fungi } & \multicolumn{6}{|c|}{ Relative enzyme activity (RA) } \\
\hline & \multicolumn{3}{|c|}{$21^{\circ} \mathrm{C}$} & \multicolumn{3}{|c|}{$28^{\circ} \mathrm{C}$} \\
\hline & 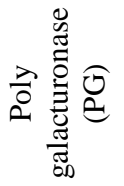 & 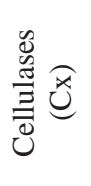 & 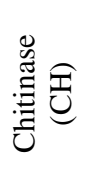 & 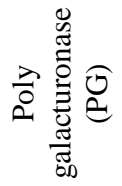 & 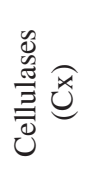 & 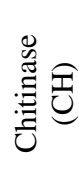 \\
\hline A. alternata & 7.0 & 0.0 & 0.0 & 17.0 & 9.0 & 13.0 \\
\hline A. solani & 9.0 & 7.0 & 9.0 & 17.0 & 17.0 & 17.0 \\
\hline C. lunata & 8.6 & 0.0 & 5.0 & 11.0 & 0.0 & 9.0 \\
\hline F. solani & 7.0 & 5.0 & 11.0 & 17.0 & 17.0 & 17.0 \\
\hline F. oxysporum & 17.0 & 11.0 & 13.0 & 17.0 & 17.0 & 17.0 \\
\hline M. phaseolina & 13.0 & 0.0 & 0.0 & 17.0 & 6.0 & 17.0 \\
\hline P. lycopersici & 17.0 & 6.0 & 9.0 & 17.0 & 17.0 & 17.0 \\
\hline R. solani & 0.0 & 0.0 & 0.0 & 17.0 & 0.0 & 17.0 \\
\hline S. botryosum & 11.0 & 0.0 & 7.0 & 17.0 & 17.0 & 17.0 \\
\hline T. viride & 17.0 & 11.0 & 8.0 & 17.0 & 17.0 & 17.0 \\
\hline Th. basicola & 17.0 & 17.0 & 7.0 & 17.0 & 17.0 & 17.0 \\
\hline$\%$ high activity & 54.5 & 27.3 & 18.2 & 100.0 & 81.8 & 100.0 \\
\hline
\end{tabular}

Egypt. J. Phytopathol., Vol. 47, No. 2 (2019) 


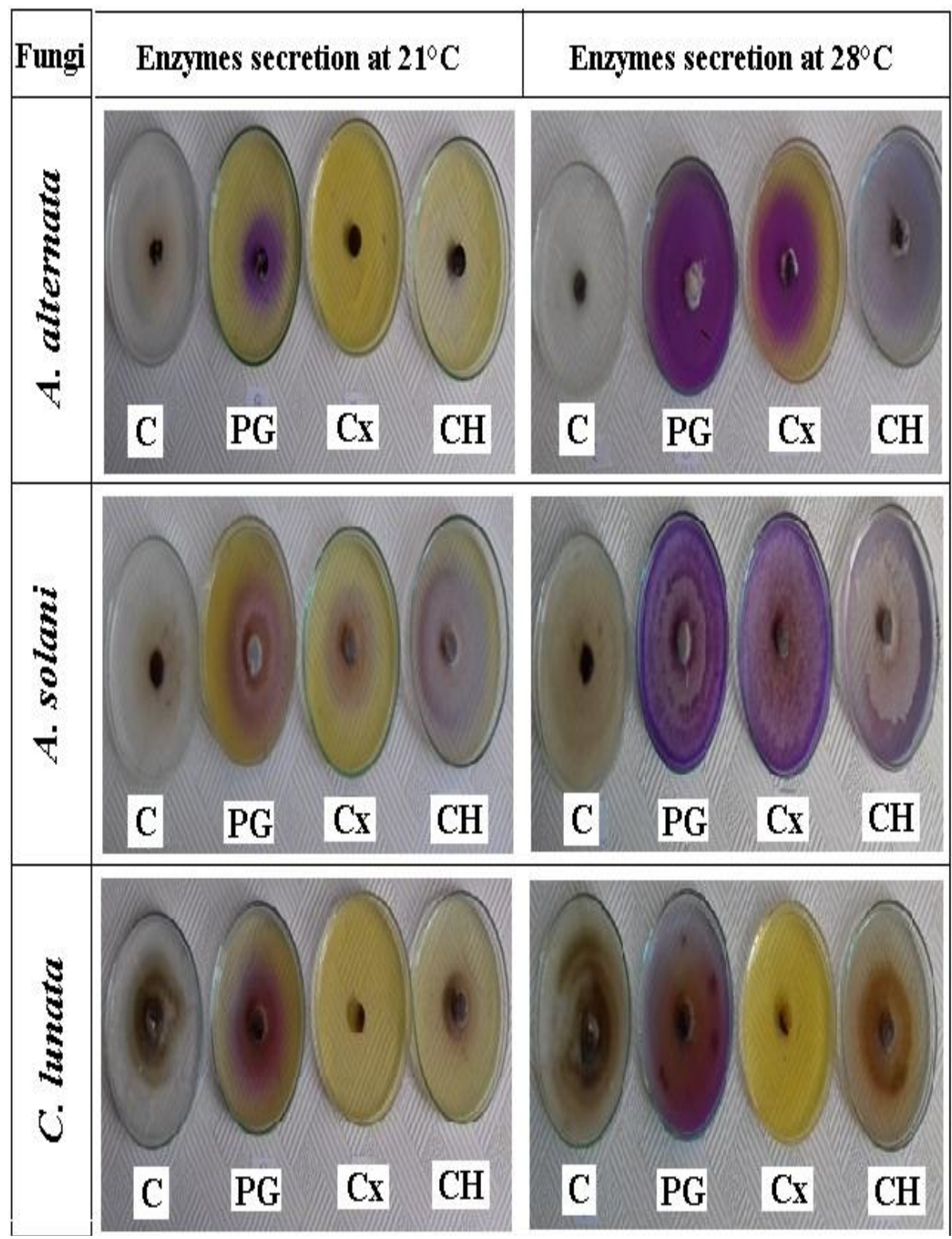

Fig. (3a): Modified agar assay for the detection of (PG), (Cx) and (CH) secreted by $A$. alternata, $A$. solani and $C$. lunata grown at 21 and $28^{\circ} \mathrm{C}$ as indicated by color change after substrate hydrolyses.

Egypt. J. Phytopathol., Vol. 47, No. 2 (2019) 


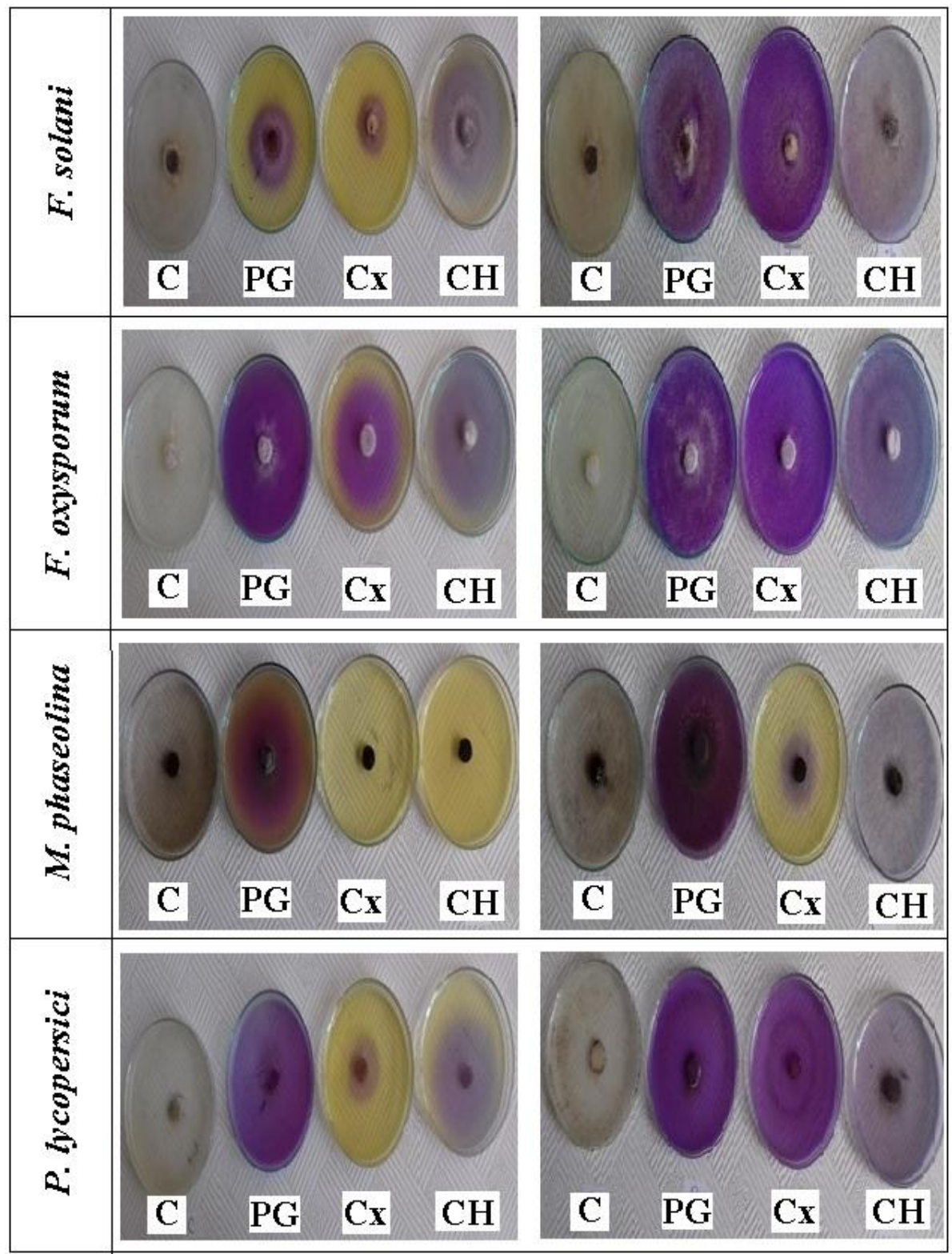

Fig. (3b): Modified agar assay for the detection of (PG), (Cx) and (CH) secreted by $F$. solani, $F$. oxysporum, $M$. phaseolina and $P$. lycopersici grown at 21 and $28^{\circ} \mathrm{C}$ as indicated by color change after substrate hydrolyses. 


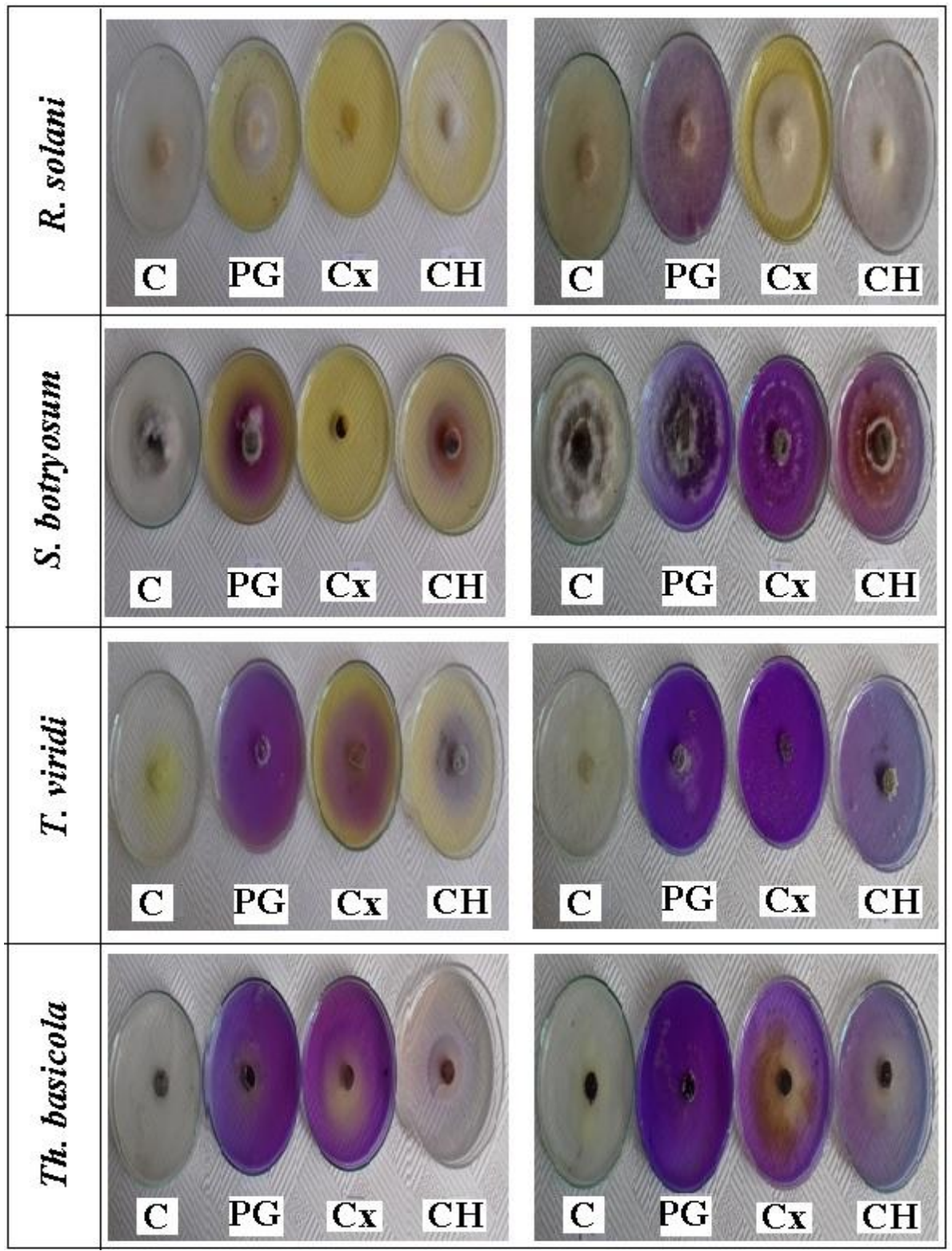

Fig. (3c): Modified agar assay for the detection of $(\mathrm{PG}),(\mathrm{Cx})$ and $(\mathrm{CH})$ secreted by $R$. solani, S. botryosum, T. viride and Th. basicola grown at 21 and $\mathbf{2 8}^{\circ} \mathrm{C}$ as indicated by color change after substrate hydrolyses.

Egypt. J. Phytopathol., Vol. 47, No. 2 (2019) 


\section{Dis c us s ion}

Propagation media to detect secretion of extracellular enzymes produced by fungi isolated from different plant organs were evaluated in earlier tired basically in broth cultures.

Modified semi solid agar medium showed that polygalacturonase (PG) was the first actively enzyme secreted at high temperature $28^{\circ} \mathrm{C}$ that is being correlated with degradation of a plant tissues along with other enzymes involved in degradation process as chitinase and cellulase.

The conclusive remarks made on this study revealed that incubation temperature is of paramount importance for growth and secretion of degradation enzymes in general. In this study, it has been shown that the most appropriate temperature for growth and enzyme(s) secretion was $28^{\circ} \mathrm{C}$ and to less extend at $21^{\circ} \mathrm{C}$, though the majority of fungi prefer. The pectin supplemented medium supported maximum linear growth for $T$. viride $(6.0 \mathrm{~cm}$.).

The first one with cellulose medium, however $T$. viride, F. oxysporum, Th. basicola supported less growth $(4.0 \mathrm{~cm}$.) and with chitin medium the isolates of $F$. oxysporum, A. solani $\left(5.0 \mathrm{~cm}\right.$.) at $21^{\circ} \mathrm{C}$ compared to maximum linear growth for all isolates, being $9.0 \mathrm{~cm}$. at $28^{\circ} \mathrm{C}$ for growth of $F$. oxysporum, $F$. solani, M. phaseolina, $R$ solani, $T$. viride, and Th. basicola.

Pectin supplemented medium showed that $T$. viride and $F$. oxysporum gave maximum linear growth, being $9.0 \mathrm{~cm}$. and cellulose medium showed that, the maximum linear growth $(8.0 \mathrm{~cm}$.) was for $T$. viride and $F$. oxysporum similar to chitin medium with $T$. viride, F. solani and $P$. lycopersici $\left(8.0 \mathrm{~cm}\right.$.) at $28^{\circ} \mathrm{C}$.

In this regard, Stelica et al. (2015) recorded similar results for F. oxysporum. Moreover, Ali and Vidhale (2013) reported that optimum temperature is the essential factor for microorganism production of essential enzymes necessary for suppression of cell viability. Similar conclusion was reported by Mishra and Khan (2015) who found that the optimum temperature for growth range of $T$. viride was ranging between $20^{\circ} \mathrm{C}-30^{\circ} \mathrm{C}$ and Arfarita et al., (2016) who reported that the optimum temperature for growth of $T$. viride was found to be between $25-27^{\circ} \mathrm{C}$.

Eleven different fungal isolates were grown in a synthetic medium with different carbon sources alternatively employed to assess the production of different cell walldegrading enzymes. Polygalacturonase (PG) activity reached its highest level on total isolates assayed at $28^{\circ} \mathrm{C}$ followed by chitinase and cellulase.

Ten isolates, i.e., F. oxysporum, F. solani, M. phaseolina, $R$ solani, T. viride, Th. basicola, A. alternata, A. solani, S. botryosum, P. lycopersici produced the highest level of polygalacturonase (PG), seven isolates i.e., T. viride, Th. basicola, A. solani, $F$. oxysporum, F. solani, P. lycopersici and $S$. botryosum produced the highest level 
of cellulase (Cx) level activity and nine isolates produced the highest level of chitinase $(\mathrm{CH})$, i.e. $T$. viride, Th. basicola, A. solani, F. oxysporum, F. solani, $P$. lycopersici, S. botryosum, M. phaseolina and $R$. solani at $28^{\circ} \mathrm{C}$.

Baayen et al. (1997) reported that $F$. oxysporum causing vascular wilt disease is characterized by a severe degradation of vascular tissue, the amount of PG activity was correlated highly with the development of the disease. Ahmad et al. (2006) mentioned that in several pathogens including M. phaseolina, pectinase was the highly activated before cellulase enzyme that initiating the process of cell wall degradation.

Kaur et al. (2012) reported that one of the isolates of $M$. phaseolina was a potential source of several hydrolytic enzymes, such as cellulase, hemicellulase and amylase. The CMCase of $F$. oxysporum, displayed significant activity within a temperature range of $25-37^{\circ} \mathrm{C}$ with maximum activity at $28^{\circ} \mathrm{C}$ as reported by Dar et al. (2013). The optimum production of cellulases by $T$. viride has been also reported at $35^{\circ} \mathrm{C}$ (Kandari et al. 2013).

Relative enzyme activity (RA) after 4 days incubation at $28^{\circ} \mathrm{C}$ for eleven isolates produced maximum polygalacturonase (17), nine isolates produced maximum chitinase (17) followed by A. alternata (13) and $C$. lunata (9) while seven isolates produced maximum cellulase (17) followed by A. alternata (9) and M. phaseolina (6) while non produced were $C$. lunata and $R$. solani $(0.0)$.

Screening of extracellular $\%$ high activity enzymes pathogenic fungi, at $28^{\circ} \mathrm{C}$, PG, $\mathrm{CH}(100.0 \%)$, and $\mathrm{Cx}(81.8 \%)$. However, the percentage of activity of enzymes of pathogenic fungi, at $21^{\circ} \mathrm{C}$ was low, $\mathrm{PG}$ gave $54.5 \%$ compared to, $\mathrm{CH} 18.2 \%$ and Cx $27.3 \%$ indicating a sharp dropin growth rate of fungi.

\section{Conclusion}

A comparison of the radial growth of fungi on modified semi-solid medium and its influence on specific enzymes secretion of the eleven isolates tested showed that both $(\mathrm{PG})$ and $(\mathrm{CH})$ had high growth rates and produced the highest enzyme secretions at either $21^{\circ} \mathrm{C}$ or $28^{\circ} \mathrm{C}$.

The results presented in this paper gave information's on the possible detection of different enzymes produced in non-liquid form, tentatively with similar consistency of plant tissues.

\section{References}

Agrawal T. and Kotasthane A.S. 2012. Chitinolytic assay of indigenous

Trichoderma isolates collected from different geographical locations of Chhattisgarh in central India. Springerplus.1(1):73.

Egypt. J. Phytopathol., Vol. 47, No. 2 (2019) 
Ahmad Y.; Hameed A. and Ghaffar A. 2006. Enzymatic activity of fungal pathogens in corn. Pak. J. Bot., 38: 1305-1316.

Ali, M.A. and Vidhale, N.N. 2013. Protease production by Fusarium oxysporum in solid-state fermentation using rice bran. Am. J. Microbiol. Res., 1: 45-47.

Amit K.C.; Shubha C.; Sushmita C. and Shridha C. 2014. In vitro and in vivo production of polygalacturonase, polymethylgalacturonase and cellulase enzymes by Alternaria solani at different incubation periods. African Journal of Plant Science. 8(5): 248-253.

Arfarita N.; Imai, T.; Kanno, A.; Yarimizu, T.; Xiaofeng, S.; Jie, W.; Higuchi, T. and Akada, R. 2016. The potential use of Trichoderma viride strain FRP3 in biodegradation of the herbicide glyphosate. Biotechnology \& Biotechnol Equipment, 27: 3518-3521.

Baayen R.; Schoffelmeer, E.A.M.; Toet, S. and Elgersma， D.M. 1997. Fungal polygalacturonase activity reflects susceptibility of carnation cultivars to Fusarium wilt. Eur. J. Plant Pathol., 103: 15-23.

Barnett, H.L. and Hunter, B.B. 1972. Illustrated Genera of Imperfect Fungi. Burgess, Minneapolis, Minnesota, USA, $3^{\text {rd }}$ ed. 20-130.

Bijesh, K.; Steni, K.T and Denji, S. 2015. Co-production of pectinase and biosurfactant by the newly isolated strain Bacillus subtills BKDS1. British Microbiol Res. J., 10(2):1-12.

Carling, D.E. and Summer D.R. 1992. Rhizoctonia. In: Methods for Research on Soil-borne Phytopathogenic Fungi. L.L. Singleton, J.D. Mihail and C.M. Rush (eds). St Paul, Minnesota, The American Phytopathological Society Press: 157165 .

Dar, R.A.; Saba, I.; Shahnawaz, M.; Sangale, M.K.; Ade, A.B.; Rather, S.A. and Qaz, P.H. 2013. Isolation, purification and characterization of carboxymethyl cellulase (CMCase) from endophytic Fusarium oxysporum producing podophyllotoxin. Advances in Enzyme Research, 1: 91-96.

Duncan, S.M.; Farrell, R.L.; Thwaites, J.M.; Held, B.W.; Arenz, B.E.; Jurgens, J.A. and Blanchette R.A 2006. Endoglucanase producing fungi isolated from Cape Evans historic expedition hut on Ross Ialsnd, Antarctica. Environ Microbiol., 8: 1212-1219.

Fernando, T.H.; Jayasinghe, C.K. and Wijesundera, R.L. 2001. Cell wall degrading enzyme secretion by Colletotrichum acutatum the causative fungus of secondary leaf fall of Hevea brasiliensis (rubber). Mycol. Res., 105:195-201. 
Ferrari, R.A.; Gaber, Y. and Fraaije, W.M. 2014. A fast, sensitive and easy colorimetric assay for chitinase and cellulase activity detection. Biotechnology for Biofuels., 7:37.

Frandberg, E. and Schnurer, J. 1998. Antifungal activity of chitinolytic bacteria isolated from airtight stored cereal grain. Can J Microbiol., 44: 121-127.

Gawade, D.B.; Perane, R.R.; Surywanshi, A.P. and Deokar, C.D. 2017. Extracellular enzymes activity determining the virulence of Rhizoctonia bataticola, causing root-rot in soybean. Physiological and Molecular Plant Pathology. 100: 49-56.

Gomes, E.; Leite, R.S.R.; da Silva R. and Silva D. 2009. Purification of an exo polysaccharide from Penicillium viridicatum RFC3 produced in submerged fermentation. International Journal of Microbiology, 1-8.

Gonzalez-Fernandez, R. and Jorrin-Novo, J.V. 2012. Contribution of proteomics to the study of plant pathogenic fungi. J. Proteome Res., 11: 3-16.

Hansford, C.G. 1946. The foliicolous ascomycetes, their parasites and associated fungi, Imp. Myc. Inst. Mycol. Pap., 15: 1-240.

Kandari, V.; Vajpayee, I.; Kumar, D. and Gupta, S. 2013. Cellulase and $\beta$ Glucosidase production by Trichoderma viride and Aspergillus wentii in submerged fermentation utilizing pretreated lignocellulosic biomass. J. Microbiol. Biotech. Res., 3: 63-78.

Karlsson, M.; Ihrmark, K.; Asmail, N.; Ubhayasekera, W.; Melin, P. and Stenlid, J. 2010. Comparative molecular evolution of Trichoderma chitinases in response to mycoparasitic Interactions. Evol. Bioinform., 6:1-26.

Kaur, S.; Dhillon, G.S.; Brar, S.K. and Chauhan, V.B. 2012. Carbohydrate degrading enzyme production by plant pathogenic mycelia and microsclerotia isolates of Macrophomina phaseolina through koji fermentation. Ind Crop Prod., 36: 140-148.

Kikot, G.E.T.; Hours, R.A. and Alconada, C.T. 2009. Contribution of cell wall degrading enzymes to pathogenesis of Fusarium graminearum: A Review Basic. Microbiol., 49: 231-241.

King, B.C.; Waxman, K.D.; Nicholas, V.; Nenni, N.V.; Walker, L.P.; Bergstrom G.C. and Gibson, D.M. 2011. Arsenal of plant cell wall degrading enzymes reflects host preference among plant pathogenic fungi. Biotechnology for Biofuels 4: pp.

Kitamura, E. and Kamei, Y. 2003. Molecular cloning, sequencing and expression of the gene encoding a novel chitinase A from marine bacterium, Pseudomonas sp. PE2, and its domain structure. App Microbiol Biotechnol., 61: 140-149.

Egypt. J. Phytopathol., Vol. 47, No. 2 (2019) 
Krishnan, A.; Alias, S.A.; Michael, W.C.V.L.; Pang, K.L and Convey, P. 2011. Extracellular hydrolase enzyme production by soil fungi from King George Island, Antarctica. Polar Biol., 4: 1535-1542.

Mishra, P.K. and Khan, F.N. 2015. Effect of different growth media and physical factors on biomass production of Trichoderma viride. PJSR., 8: 11-16.

Mogensen, J.M.; Nielsen, K.F.; Samson, R.A.; Frisvad, J.C. and Thrane, U. 2009. Effect of temperature and water activity on the production of fumonisins by Aspergillus niger and different Fusarium species. BMC Microbiology (BioMed Central Microbiology)., 9: 281.

Neergaard, P. 1945. Danish species of Alternaria and Stemphylium: Taxonomy, Parasitism, Economical Significance. Oxford Univ. Press, London, 560.

Nelson, P.E.; Toussoun, T.A. and Marasas, W.F.O. 1983. Fusarium species: An Illustrated Manual for Identification. Pennsylvania State University, University Park. 193.

Okunowo, W.O.; Gbenle, G.O.; Osuntoki, A.A.; Adekunle, A.A. and Ojokuku, S.A. 2010. Production of cellulolytic and xylanolytic enzymes by a Phytopathogenic Myrothecium roridum and some a virulent fungal isolate from water hyacinth. Afr. J. Biotechnol., 9: 1074-1078.

Ramanathan, G. and Vinodhkumar, T. 2013. Evaluation of toxigenic potential of secondary metabolite from Fusarium oxysporum. International Journal of Science Innovations and Discoveries (IJSID)., 3: 231-242.

Rifai, M.A. 1969. A revision of the genus Trichoderma. Mycological Papers; 116: $1-56$.

Schickler, H.; Haran, S.; Oppenheim and Chet, I. 1998. Induction of the Trichoderma harzianum chitinolytic system is triggered by the chitin monomer, $\mathrm{N}$-acetylglucosamine. Mycological Research, 102(10): 1224-1226.

Sharma, C.K.; Vishnoi, V.K.; Dubey, R. and Maheshwari, D.A. 2018. Twin rhizospheric bacterial consortium induces systemic resistance to a phytopathogen Macrophomina phaseolina in mung bean. Rhizosphere, 5: 71-75.

Sharma, R. and Rajak, R.C. 2003. Keratinophilic fungi: Natural keratin degrading machines; their isolation, identification, and ecological role. Resonance., 8: 2840 .

Sherief, A.A.; El-Tanash, A.B. and Atia, N. 2010. Cellulase production by Aspergillus fumigatus grown on mixed substrate of rice straw and wheat bran. Res. J. Microbiol., 5: 199-211. 
Snedecor, G.A. and Cochran, W.G 1980. Statistical Methods, $7^{\text {th }}$ Ed., The Iowa State Univ., Press, Ames., Iowa, U.S.A. pp. 507.

Stelica, C.; Gheorghe, B.A.; Relu, Z.C. and Maria, O. 2015. The biological growth parameters of the Fusarium oxysporum f. sp. glycines fungus. Romanian Biotechnological Letters, 20: 10921-10928.

Teather, R.M. and Wood, P.J. 1982. Use of Congo red Polysaccharide interactions in enumeration and characterization of cellulolytic bacteria from the bovine rumen. Applied and Environmental Microbiology, 43: 777-780.

Vallejo-Herrera M.D.; Toro M.E.; de Figueroa, L.I.C. and Vazquez F. 2004. Extracellular hydrolytic enzymes produced by phytopathogenic fungi J.F.T. Spencer, A.L. Ragout de Spencer (Eds.), Methods in biotechnology: environmental microbiology: methods and protocols, Humana Press, Totowa, New Jersey, 399-421.

Yang, Z.M.; Bi, Y.; Li, Y.C.; Kou, Z.H.; Bao, G.H.; Liu, C.K.; Wang, Y. and Wang, D. 2012. Changes of cell wall degrading enzymes in potato tuber tissue slices infected by Fusarium sulphureum. Scientia Agricultura Sinica., 45(1): 127-134.

Zhang, J.; Bruton, B.D. and Biles, C.L. 2014. Cell wall-degrading enzymes of Didymella bryoniae in relation to fungal growth and virulence in cantaloupe fruit. European Journal of Plant Pathology, 139(4): 749-761.

Zhao, Y.Q.; Wu, Y.H.; Fu, Y.; Zhao, X.X. and Chen, J.G. 2014. Activity pathogenic effect of cell wall degrading enzyme in tobacco target spot pathogen Rhizoctonia solani. Tobacco Science \& Technology, 11: 84-88.

Zhou, S.; Liu, Y.; Zhang, M.; Li, B.D.; Chen, X.J. and Liang W.X. 2016. Comparison of the virulence and cognate virulence factors of multinucleate, binucleate and uninucleate Rhizoctonia isolates, causing sheath blight on maize plants. European Journal of Plant Pathology, 145(2): 501-506.

Corresponding author: Muhanna, N.A.S.

E-mail: naglaa_muhanna@yahoo.com

(Received 13/10/2019;

in revised form 20/10/2019)

Egypt. J. Phytopathol., Vol. 47, No. 2 (2019) 


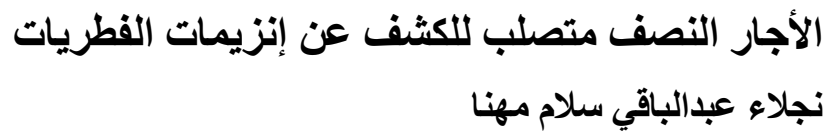

معهد بحوث أمراض النباتات ، مركز البحوث الزراعية ، الجيزة ، مصر

تم عزل وتعريف 11 1 عزله من الفطريات الممرضه للنبات وهى كالتالى

A. alternata, A. solani, $C$. lunata, $F$. solani, $F$. : oxysporum, $M$. phaseolina, $P$. lycopersici, $R$. solani, $S$. botryosum, Th. basicola,

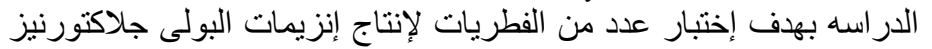

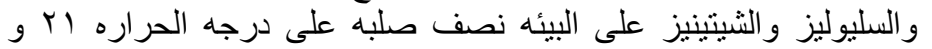

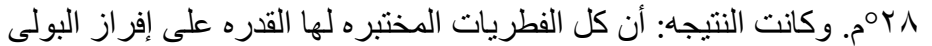

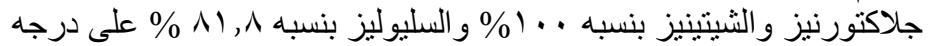

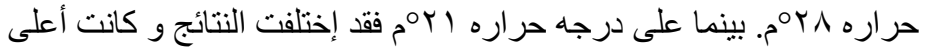

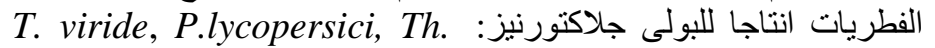
basicola, F. oxysporum, M. phaseolina, S. botryosum,

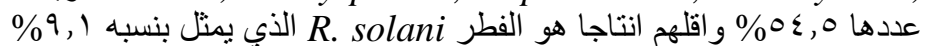

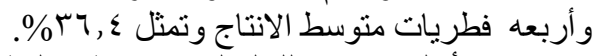

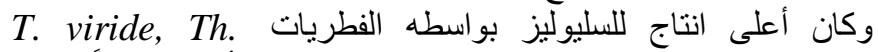
F. oxysporum و وتمثل r. basicola, و A. alternata, C. lunata, M. phaseolina, R. solani $\% \leqslant 0,0$ و الباقى منوسطه الاتتاج وتمثل r. S. botryosum الفطريات المختبرة.

F. solani, F. كما وجد أن اعلى انتاج للثيتينيز كان من الفطريات والنيات

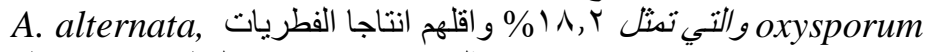
ا M. phaseolina, R. solani

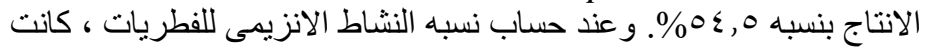

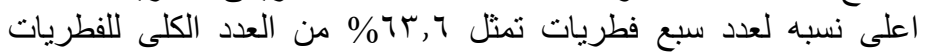

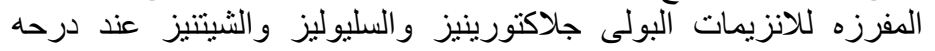

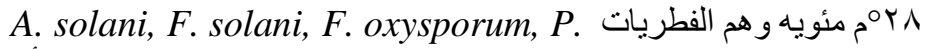
lycopersici, S. botryosum, T. viride, Th. basicola

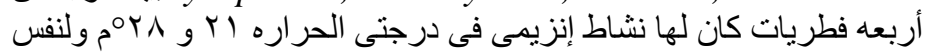
F. oxysporum, P. lycopersici, T. viride, فتره التحضين ع ايام و وهم

Th. basicola

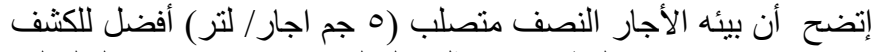

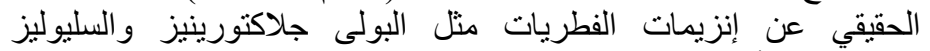

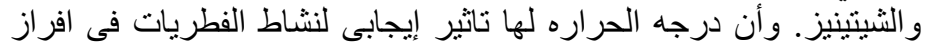

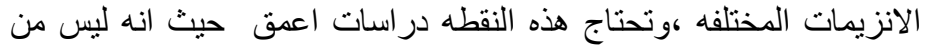
الثائع تقدير الانزيمات فى البيئه المنصلبه. 